\title{
Chinese model for mass adventure tourism
}

Ralf Buckley ${ }^{\mathrm{a}}{ }^{*}$, Kristen McDonald $^{\mathrm{a}}$, Lian Duan ${ }^{\mathrm{b}}$, Lin Sun ${ }^{\mathrm{b}}$, Lan Xue Chen ${ }^{\mathrm{b}}$

a International Chair in Ecotourism Research, Griffith University, Gold Coast, Qld 4222, Australia

${ }^{\mathrm{b}}$ Ecotourism Research Institute, Southwest Forestry University, Kunming 650224, China

\section{HIGHLIGHTS}

- Domestic experiences shape outbound expectations.

- Chinese rafting is passive mass tourism in modified rivers.

- Western rafting expects individual safety responsibility.

- Chinese model has $~ 80$ million participants already.

- Cultural differences apply across outdoor tourism.

Keywords:

Sustainability, Rafting, Economics, Expectations, Outbound, Culture

\begin{abstract}
China has evolved a new domestic model for river-based adventure tourism, a form of passive mass tourism characterised by short trips, in small unguided rafts without paddles, on heavily modified watercourses with exclusive control of access, receiving up to 10,000 clients per site per day. This is very different to international models, which expect much greater individual involvement and responsibility for safety. Client satisfaction is moderate and repeat business low, but the Chinese domestic model nonetheless generates a billiondollar annual turnover nationwide, with participation to date by around one quarter of China's 18-35 year-olds. This domestic model shapes the expectations of Chinese tourists travelling overseas, with implications for practical safety and satisfaction, and theoretical tests of culturelinked expectation disconfirmation.
\end{abstract}

\section{Introduction}

Most recent analyses of adventure tourism indicate a high degree of homogeneity worldwide, with participants travelling internationally to undertake the same activities in different places (Beedie \& Hudson, 2003; Buckley, 2006, 2007, 2010a; Carnicelli-Filho, Schwartz, \& Tahara, 2010; Houge Mackenzie \& Kerr, 2012, 2013; Swarbrooke, Beard, Leckie, \& Pomfret, 2003). Here, in contrast, we describe and analyse a large-scale adventure tourism activity with $\sim 100$ million participants, which is restricted solely to mainland China, and has previously been 
described only in Chinese-language academic and popular literature. We argue that this domestic model shapes expectation of outbound Chinese tourists, with broader implications. The activity, known as piaoliu, involves descents of heavily-modified low-flow natural watercourses in small unnavigable rafts, with up to 10,000 clients per day. It has some similarities to a fairground flume ride (Poff, Larson, Spencer, \& Shimoda, 2006) and some to Western-style whitewater rafting (Buckley, 2009), but is different from both.

There are apparently no previous examples where any commercial tourism activity has reached such a large scale without any analysis in the Anglophone travel literature. It seems that this has happened partly through linguistic confusion. The direct Chinese translation for rafting is piaoliu, but the direct English translation for piaoliu is river drifting. In China, piaoliu refers both toWestern-style whitewater rafting, offered commercially by a small number of expatriate tour operators on the great rivers of the western provinces; and also to Chinese-style whitewater drifting, offered commercially on much smaller whitewater watercourses in the eastern provinces. Most of the Chinese operations are known as piaoliu ziyou, free river drifting, which means that there are no guides, oars or paddles.

In the English-language literature, Western whitewater rafting tourism has been examined from a variety of perspectives, including product structure and packaging (Buckley, 2006, 2007, 2009); communications (Buckley, 2010b); client motivations (Buckley, 2012; Fluker \& Turner, 2000); client experience (Holyfield, 1999; Holyfield \& Fine, 1997; Jones, Hollenhorst, Perna, \& Selin, 2000; Wu \& Liang, 2010); guide choreography (Arnould \& Price, 1993; Arnould, Price, \& Otnes, 1999); emotional labour (Houge Mackenzie \& Kerr, 2013; Jonas, 1999) and economics (Northeast Natural Resource Centre [NNRC], 1997; Siderelis \& Moore, 2006). All of these studies assumed that the Western model of whitewater rafting is standard, and few felt it necessary even to describe that model in any detail.

In Chinese-language academic analyses of piaoliu, the main focus has been on the strengths and weaknesses of commercial operations and management systems (Chen, Luo, \&Wen, 2001; Hu \& Wang, 2008; Huan, 2009; Li \& Bao, 1995; Li \& Zhong, 2007; Lu \& Lin, 2009; Luo, 2008; Qin, Jiao, \& Yan, 2009; Wang, 2005; Wen, Chen, \& Yang, 2002; Wu, 2007; Xia \& Liu, 2009). Lin and Li (2004) and Zhou, Luo, and Chen (2007) examined the advantages of operational standardisation. Yang, Huang, Li, and Chen (2006) argued that improved environmental management would help in brand building. Kong, Huang, and Zhu (2005) 
investigated the role of climatic variability on rafting in Zhejiang Province. Zong and Zhi (2007) examined risks from landslides. Fu, Tian, and Tong (2009) identified scenery as the key influence on satisfaction for 150 piaoliu participants in Sichuan. All of these Chineselanguage analyses assumed the Chinese model of piaoliu as standard, and none described it in any detail or compared it to Western approaches.

There are thus two separate bodies of research literature, published in different languages in different journals. By studying the Chinese tourism products and tourist motivations directly, we show here that the English-language and Chinese-language literatures actually describe different activities. Very few Chinese citizens have taken part in Western-style whitewater rafting, because these tours are expensive and require prior outdoor experience; and very few inbound Western tourists have purchased piaoliu tours, because these are advertised only in Chinese and sold largely as components of domestic tour packages. From a practical perspective, Chinese tourists familiar with piaoliu, who purchase whitewater rafting tours in other nations, will find that theWestern product does not at all match their prior experience and expectations. This has significant implications both for safety and for satisfaction.

Here, therefore, we used a mixed methods approach to characterise and analyse the Chinese domestic whitewater adventure tourism sector. Our first aim is simply to document a large and previously undescribed component of the global tourism industry. Our second aim is to provide a basis for comparison with similar sectors internationally. Our third aim, perhaps of greatest general interest, is to show how an apparently small cross-cultural misunderstanding, in this case from translation of the terms rafting and piaoliu, can generate significant practical concerns for the safety and satisfaction of tourists travelling overseas.

\section{Methods}

We analysed the Chinese domestic piaoliu industry in five successive steps. First, we identified and mapped all known commercial operators in the subsector. To do this, we used a combination of Chinese-language internet searches, domestic travel-agent brochures and other marketing materials, regional tourism organisation catalogues and portfolios, and snowball sampling of those involved in the industry. This is the same approach which would be used to generate a database of commercial operators in any country and industry subsector. Second, we selected a set of leading operators, using four criteria: greatest geographical concentration of operators; longest history of operations; largest numbers of 
clients; and most conspicuous and ubiquitous marketing. We obtained this information from the same sources as above, plus the websites and marketing materials of each of the operators. We used these criteria in order to select the core or archetypes of the piaoliu sector, those operators which best represent patterns in the sector as a whole.

Thirdly, we conducted on-site audits of each of the selected enterprises, in order to characterise typical piaoliu products. Kristen McDonald, and in some cases also Duan Lian, Sun Lin, Chen Lan Xue visited each of these companies, took part in their tours, observed operational procedures, and conducted informal interviews with staff and clients. We took particular note of aspects such as: the scale of operations, the length of each tour in both time and distance, modifications to watercourses, the types of watercraft used, the mode of embarkation and disembarkation, the proportions of clients arriving on package tours, client preparedness and clothing, loan or sales of equipment and accessories, the content of pre-trip briefings, safety equipment and procedures, aspects of environmental management such as litter control, and the behaviour of clients and staff both on and off the water.

Fourth, we examined client motivations and satisfaction through a large-scale quantitative analysis. Chinese-speaking researchers KM, DL, SL, CLX distributed Chinese-language survey questionnaires on-site to 2080 tour participants, immediately after disembarkation. The authors also provided verbal explanations and further details if requested, and collected completed questionnaires. The surveys contained standard questions on participant demographics, and asked participants to rate the importance of 11 independent factors for motivation and 11 for satisfaction, using 5-point Likert scales. For analysis, we first compared response patterns for each of the 22 items independently, between the different sites and enterprises and between participants of different age and gender, to check whether they should be considered jointly or separately for subsequent analysis. We then graphed the frequencies of each Likert-scale response, for each of the 11 motivation factors and each of the 11 satisfaction variables separately. We used broken-stick graphs, which enable patterns to be visualised and compared directly, and also allow assessment of central tendency cf bipolarity in each set of responses. Broken-stick displays are commonplace in other disciplines. They are apparently novel, but nonetheless valuable, for presentation of Likertscale data in tourism research. To test statistically for any differences in response patterns between the 11 items in each set, we used the amalgamated chi-square technique adopted by Ollenburg and Buckley (2007). That is, we aggregated the two lowest (negative) and two 
highest response (positive) categories for each factor, ignoring the central or neutral response; arranged the factors from highest to lowest ratio of positive to negative aggregate scores; and tested for differences between adjacent factors using $2 \times 2$ chi-square tests. We used this coarse but robust categorical approach, since Likert-scale responses are ordinal variables. Post-hoc range tests based on $t$-test statistics derived from means and standard errors, though widespread for Likert-scale data in social sciences research, are not strictly valid statistically.

Fifth, we conducted a small-scale qualitative study, through semi-structured interviews with 27 senior stakeholders in the industry. These included: enterprise owners and managers, lifeguards and guides, sports and travel bureaus, the National Watersports Bureau, and relevant research organisations. We identified these individuals in two stages. First, we used subsidiary information compiled while constructing our national database, together with a large-scale snowball sampling of individuals involved, to produce a list of stakeholders across all components of the piaoliu sector.We then stratified this list by stakeholder groups as above, and constructed a ranking of approximate seniority within each group, based on position title and reputation amongst other stakeholders. We contacted the senior representatives individually and requested interviews, and if any proved uncontactable or unwilling, we moved to the next most senior.We used the results of these interviews in order to understand the history and politics of the piaoliu sector, and to triangulate our findings from the on-site audits and participant questionnaires. In view of the heterogeneity of our interviewees and the relatively small total number of interviews, we did not conduct a standard deconstruction/reassembly analysis of qualitative concepts. All procedures adopted for each of these approaches followed the ethical requirements of Southwest Forestry University.

\section{Results}

\subsection{Piaoliu enterprises}

We identified 346 piaoliu operations in total. Geographically, these are concentrated in southern and eastern provinces, especially Zhejiang (44 operators), Hunan (30) and Hubei (28). The distribution of tour operations thus depends more on the population demographics of potential clients than the geography of raftable rivers. The same applies for other adventure tourism activities and other countries (Buckley, 2010a; pp. 17-30). Using the criteria listed above, we selected seven enterprises, listed in Table 1, for detailed on-site audit and participant surveys. For these enterprises, Table 1 summarises: enterprise structures and 
site access; watercourse features and modifications; operating seasons and trip structures; and the commercial design of the products.

Of these seven enterprises, six are accessible on a day trip from a major urban centre, and these urban centres are either large source markets themselves, in the case of Guangzhou and Chengdu, or major tourism destinations, in the case of Zhangjiajie (Table 1a). All of them use low-volume watercourses with extensive modifications, many also with flow control dams. For all save one (Maling), the rapids are Grade II, runnable with little risk. Peak season is in summer, from April until October, because of warmth and weather conditions for clients, who are not outfitted with wetsuits. The river sections used are rather short, down to $3 \mathrm{~km}$ in the case of Xuangzhen; and for five of the tours, the trip takes 90 min or less (Table 1b).

Two main types of rafts are used, small unguided paddle-less two-person oval rafts on the lowest-flow watercourses, and larger 8-10 passenger pontoon rafts with a guide and either paddles, a pole or in one case a motor, for the somewhat higher-flow rivers. For the former, safety is provided by lifeguards stationed on the riverbanks. At Huangteng, there are 136 lifeguards over a $5 \mathrm{~km}$ watercourse, representing an average spacing of $36 \mathrm{~m}$ between lifeguards. Except for Maling, all these enterprises receive over 3000 clients per day, up to 10,000 per day for Huangteng. They charge from CNY120-260 per passenger, with the highest prices at Huangteng, which is one of the shortest runs (Table 1c). Four of the seven enterprises, including the largest, are entirely private corporations which have leases of 20-50 years for access to land and water. The other three are local government enterprises or public/private partnerships (Table 1d).

\subsection{Piaoliu cf. western rafting}

Key differences between piaoliu and Western whitewater rafting are compared in Table 2. There are differences in: waterway, watercraft, clothing, safety, access, duration, volume, price, enterprise structure, and marketing. In broad terms, most Western whitewater rafting tours operate with non-exclusive access arrangements to unmodified watercourses, largely on public lands. The majority operate on rivers whose flow depends on natural rainfall and runoff. Some operate on rivers whose flow is controlled by dam releases, but these releases are commonly driven by unrelated requirements such as crop irrigation or hydroelectric power generation, not by rafting. These enterprises use guided rafts with active propulsion and steering, with clients relying on the guide for safety (Buckley, 2006, 2009). Piaoliu tours, 
in contrast, operate with exclusive access to short, heavily modified watercourses, often with water flows controlled by deliberate releases from upstream dams which are built, owned and operated for this purpose by the piaoliu enterprises themselves. Most piaoliu tours use small unguided rafts with no propulsion or steering, and safety depends on lifeguards along the banks. The immediate appearance of piaoliu is of multitudes of small unguided two-person rafts flushed in an uncontrolled manner down narrow flume-like channels with lifeguardstudded banks.

Underlying these operational differences is a very different business model. Rivers used by most Western whitewater rafting companies are managed by public agencies which determine how many rafts can launch each day, what equipment they must carry, how they must behave, and in some cases, what prices they can charge. They compete partly on places and prices, but largely on service and safety. This also applies for Western-style whitewater rafting operators in China. Piaoliu operators, in contrast, invest in fixed assets, namely exclusive access to a watercourse which they modify so as to maximise daily customer volume. Many of the watercourses used are raftable only because of channel modifications which essentially convert natural streams to artificial flumes (Poff et al., 2006). These modifications include: removal of natural hazards; channelisation using concrete and rock; artificial rapids and pools; riprap rockwalls; flow-control dams andwater transfers; and concrete launch and landing sites. Some of the landing sites, in particular, are modified using flow-control chutes and training walls or buoy lines, which flush the rafts automatically onto a concrete ramp or pool area, so the clients can easily disembark.

According to interviews with piaoliu entrepreneurs, this model originated as a tool to sell two-person rafts, which have been manufactured by a local entrepreneur since the late 1990s. That is, instead of designing watercraft to run rivers, this model modifies watercourses to suit the rafts. In most of these operations, the clients are not given paddles, since according to raft company owners, the clients do not know how to use paddles and are likely to be injured by inadvertently striking each other. This is the form of floating called piaoliu ziyou, free drifting. In some of the higherflow rivers, the piaoliu operators use larger rafts consisting of two or three pontoons, which the clients sit astride, and a guide steers by paddling or by punting with a pole. One of the enterprises audited, Maoyan (Table 1), uses pontoon rafts steered with an outboard motor. There is no client training at any of the sites audited, either in rafting technique or in safety procedures. Helmets and lifejackets are provided, but are often 
ill-fitting, unfastened, or wrongly worn. Clients wear their own clothing and footwear. Only one of the enterprises audited issues river shoes to clients, to reduce foot injuries. All these factors differ greatly from Western whitewater rafting practices and products.

\subsection{Sector scale and structure}

Based on the prices, volumes and seasons listed in Table 1, with allowances for variability, the seven piaoliu enterprises audited here have a collective annual turnover of over one billion yuan, about US\$160 million. If the rest of the industry nationwide operates at similar scale, the annual turnover of the piaoliu sector would be over 50 billion yuan, US $\$ 8$ billion. Even if enterprises elsewhere in China operate at only a tenth this scale, piaoliu is already a billion-dollar industry nationwide. For comparison, if the three great rivers of Western China, now under threat from hydroelectric development (Magee \& McDonald, 2006; McDonald, 2007; Qiu, 2012; Shan Shui Society \& Liu, 2011; Stone, 2011) all established whitewater rafting industries paralleling the Colorado Grand Canyon, USA, this could generate $\sim$ US $\$ 200$ million annually (Buckley, 2010c). The economic scale of piaoliu is thus already larger than the potential scale of Western-style whitewater rafting in China.

At several sites, operators stated that $>80 \%$ of customers are on package tours where the piaoliu experience is just one of a series of activities. This is currently commonplace for all forms of domestic tourism in China (Huang \& Weiler, 2010). The Qingyuan piaoliu tours (Table 1) are available as day trips from Guangzhou. The Zhangjiajie tours (Table 1) include visits to Zhangjiajie National Park, local homestays (nongjiale), restaurants serving local food, and ethnic-minority cultural performances (Gao, Huang, \& Huang, 2009; Yang \& Wall, 2008). Piaoliu enterprise operators prefer shorter trips so that they can accept more clients each day, and package tour operators prefer shorter trips so they can offer more activities, each with its own profit component, each day. Some of the piaoliu enterprises offer multiple activities at their own operating sites. These include cablecars, paintball skirmishes and ropes courses, hiking trails and swimming pools, as well as catering and accommodation facilities.

By Western standards, all the piaoliu enterprises are mass tourism. Indeed, at least two of the seven enterprises audited were aiming to obtain ' $4 \mathrm{~A}$ ' mass tourism certification from China's National Tourism Administration; and two others are adding new facilities to attract more tour groups. Despite the high customer volumes, substantial environmental impacts, and highly modified settings, the piaoliu operators and other tourism stakeholders interviewed for 
this study market piaoliu products as shengtai luyou, the Chinese analogue of Western ecotourism (Buckley, Zhong, Cater, \& Chen, 2008).

Current business models for piaoliu are endorsed by local government agencies and industry associations. The two highest-volume enterprises studied here, Huangteng and Xuanzhen, are promoted nationwide as the Qingyuan model. These are both operated by private corporations, and both have: short trips (three to five $\mathrm{km}, 1.5 \mathrm{~h}$ ); heavily modified watercourses; very low river flow $\left(0.8 \mathrm{~m}^{3} \mathrm{~s}^{-}{ }^{1}\right.$, or $\left.<30 \mathrm{cfs}\right)$; small, two-person paddle-less rafts of the piaoliu ziyou type; and numerous lifeguards on the stream banks. Both are in Qingyuan County, which now promotes itself as 'China's Piaoliu County'. According to interviewees from the local government tourism bureau, this model generates a positive return on investment within a year, whereas most tourism developments have payback periods of 10-20 years or longer. Entrepreneurs and government personnel from elsewhere in China visit Qingyuan specifically to study this model.

The Qingyuan model is also endorsed by China's National Watersport Bureau (NWB), a central government body which promotes and standardises watersports. The National Watersport Bureau legitimises and consolidates its authority by sponsoring piaoliu competitions, for which it is paid by the piaoliu enterprises and local governments. Four of the seven sites studied here have hosted such competitions, which they see as useful for marketing and for building guanxi, connections with government officials. Guanxi are a critical component in successful business in China, in tourism as in other sectors (Ryan \& Huang, 2013).

\subsection{Client motivations and satisfaction}

Of the 2080 client questionnaires distributed, 1248 (64\%) were completed and 1100 (53\%) were useable. Differences between client characteristics and experiences at the seven sites were small, and results are presented here in aggregate. Approximately $60 \%$ of respondents were male. Most were young, with 35\% aged 18-25 and 35\% aged 26-35. Most were welleducated. Three quarters had been to college or university, as compared to $6.5 \%$ of China's population overall (China, National Statistics Bureau, 2008), and 26\% of the population aged 18-35 (UNESCO, 2012). Most of the participants live in urban areas and earn above-average incomes. Over half had not taken part in piaoliu tours previously, though $7 \%$ had done so six times or more, and $93 \%$ take part regularly in other outdoor adventure activities. Almost all 
(95\%) were keen to take part in piaoliu tours again, but fewer than one quarter overall planned to repeat the tour at the same site.

Client ratings of motivational factors are shown in Fig. 1. The factor names are abbreviated translations of the relevant survey questions in Chinese. Two factors, namely nature and relaxation, were rated as important or highly important by $>80 \%$ of respondents. This is a significantly higher rating $(p<0.001)$ than for the remaining factors, using the robust aggregated chi-square approach (Ollenburg \& Buckley, 2007). Two factors, namely friends and package tours, were rated as unimportant by $>70 \%$, a significantly lower rating $(p<$ 0.001) than for the other factors. However, participants on package tours may be underrepresented in the sample, since in some cases their leaders urged them to hurry along and not respond to the questionnaire surveys. Other factors such as scenery, culture, exercise, escape, fun, challenge, and learning, were considered important by $40-60 \%$ of respondents (Fig. 1).

Client satisfaction was moderate (Fig. 2). As for Fig. 1, the factor names shown in Fig. 2 are abbreviated translations of the relevant survey questions in Chinese. About $75 \%$ of respondents reported that they were broadly satisfied overall, and 50-70\% said they were satisfied with scenery, landscape protection, equipment, instructions, safety, comfort and excitement. That is, most of the respondents gave somewhat equivocal responses in regard to all these issues (Fig. 2). Overall, 70\% of clients would have preferred a longer trip; though at Mengdong, with a 2.5 -h tour, only $46 \%$ of clients gave this response. About one tenth (10$12 \%$ ) of respondents overall were dissatisfied or very dissatisfied with three particular factors, namely the quality of instructions provided, the quality of equipment, and the protection of the natural landscape. Although these proportions are small, they are significantly higher $(p<0.001)$ than the proportions $(<8 \%)$ expressing dissatisfaction with other factors such as the degree of excitement. This thus indicates customer concern over these aspects of the experience.

Overall, it seems that piaoliu enterprises have designed their products to offer young, educated Chinese clients just enough to be considered acceptable and continue to attract new customers. It also appears that they could improve client satisfaction rather easily and cheaply by providing better safety equipment and pretrip briefings, and better environmental management, eg. by simply asking clients not to drop litter. For international inbound 
adventure tourists who have experienced Western-style whitewater rafting products in western China, the piaoliu ziyou products of Qingyuan are a disappointment. The 18,000 young Chinese domestic adventure tourists who purchase the Huangteng or Xuanzhen products each day, however, are suffiently satisfied with that experience that $95 \%$ would buy another piaoliu tour, albeit at a different site.

\section{Conclusions}

Piaoliu is a billion-dollar mass tourism activity, and a major component of the Chinese domestic adventure tourism industry. Over the past three years, some 15-20 million young Chinese tourists have purchased at least one of the seven piaoliu products outlined here. Allowing for repeat purchases, this yields an estimate of $\sim 80$ million or more nationally. This is a around one quarter of the $\sim 300$ million Chinese citizens currently aged 18-35. In addition, participation in piaoliu is growing. Huangteng, the largest enterprise with $\sim 10,000$ clients per day, reported significant growth. Chinese domestic tourism as a whole grew by 24\% per annum between 2000 and 2010 (China Tourism Academy, 2012).

Currently, the Western and piaoliu approaches to whitewater adventure tourism in China are complementary. The piaoliu ziyou approach, with unskilled and powerless passengers in very small rafts, would be very dangerous on the large rivers of western China. Equally, the Western approach would be unsuited to the very low-flow watercourses of Qingyuan. Of the seven piaoliu enterprises studied here, that at Maling (Table 1) seems closest to the Western model, since it operates on a relatively unmodified watercourse flowing at $80 \mathrm{~m}^{3} \mathrm{~s}^{-1}$ (2800 cfs), using large pontoon rafts with a guide and eight to fifteen passengers on each, totalling $<600$ clients per day. It remains to be seen whether Chinese tourists who have experienced piaoliu may later seek out and try Western-style whitewater rafting within China. Currently, however, the two sectors seem to be quite unconnected.

Piaoliu exists only within mainland China. This contrasts strongly with previous analyses of the adventure tourism subsector. These have reported global homogeneity in products and infrastructure, equipment and clothing, and professional standards (Buckley, 2006, 2010a, 2012). Thus, for example, ski lifts operate in the same way worldwide; diving qualifications operate internationally (PADI, 2012); and whitewater rafting tour operators use the same communication systems (Buckley, 2010b). Previously recognised cultural differences between countries are small: e.g. in the design of boats (Buckley, 2006) or saddles 
(Ollenburg, 2006); the format of the 'flying kilometre' ski race (Midol \& Broyer, 1995); guide attitudes in whitewater rafting (Farooquee, Budal, \& Maikhuri, 2008; Serenari, Leung, Attarian, \& Franck, 2012); or the combination of sports and leisure as "lepocheu" in Korea (Lee \& Jennings, 2010). The potential effect of cultural and linguistic differences on safety in whitewater rafting operations has been noted previously for Japanese tourists in Australia, (Buckley, 2006), but not examined in detail.

The existence and operations of piaoliu, however, show that contrary to these previous perspectives, adventure tourism is indeed culturally heterogeneous, in the same way as other types of tourism. There is an extensive and longstanding research literature showing that the existence and evolution, mechanisms and manifestations, conflicts and commodification of tourism are all culturally driven and determined (Boniface, 1998; Dann \& Cohen, 1991; MacCannell, 1976; Nash \& Smith, 1991; Salazar, 2012; Stronza, 2001). For example, there are cultural distinctions between tourism in Europe and other Western continents, and the highly populous and newly wealthy Asian nations, with or without past colonial heritage (Buckley et al., 2008; Cater \& Lee, 2006; Mok \& deFranco, 2000; Sofield \& Li, 1998, 2011; Vespestad \& Mehmetoglu, 2010; Winter, 2009).

The key reason previously advanced for international homogenisation in adventure tourism was that most of these activities originated in Western nations, and were carried worldwide by Western tourists in search of new sites (Buckley, 2010a; Buckley \& Ollenburg, 2012). Populous and newly wealthy nations with little past European influence, colonial or otherwise, however, now have their own domestic tourism industries, including adventure tourism. The domestic tourism industry in China is very large, >2 billion trips per year. Many of China's younger generation have the means, interest and freedom to travel inside their own country, and now pursue activities based on nature, culture and adventure (Han, 2006; Huan, 2007). This reflects growth in active outdoor tourism within a number of Asian nations (Cater $\&$ Lee, 2006). Piaoliu has arisen within this context.

The expectations of outbound Chinese tourists are formed at least in part by their own culture, including previous experiences of domestic tourism in China. Chinese international outbound tourism is currently estimated at 78 million trips per year, growing at 20-24\% annually (China Tourism Academy, 2012; Thompson, 2012). As destination countries compete to attract wealthy Chinese tourists, they must adapt to these expectations, in the 
same way that other countries have adapted historically to the expectations of outbound tourists from the UK, Europe, USA and Japan. There is now a cohort of $~ 80$ million young, educated Chinese, wealthy enough to travel, who have experienced piaoliu. At least some of these will travel overseas and purchase the closest analogous products internationally, which are Western whitewater rafting products. They will expect piaoliu, but they will find themselves on all-day or multi-day tours, running natural rivers with natural hazards, where they are expected to paddle vigorously, and to swim and self-rescue if they fall out.

From a commercial perspective, this suggests that international raft tour operators could gain, not by copying piaoliu, but by learning how piaoliu shapes Chinese clients' expectations. In particular, our results suggest that safety considerations, including Chinese-language briefings and pre-trip training, should be of particular concern for international raft tour operators accepting Chinese clients; and that good safety equipment and training would also increase satisfaction for Chinese clients. Raft tour operators could also increase satisfaction for young Chinese clients by emphasising environmental management. From a marketing perspective, international raft tour operators could gain by establishing guanxi, connections and marketing alliances, with the Chinese domestic piaoliu enterprises, who could supply them with a high-volume stream of potential clients. No such links are currently known.

From a research perspective, the piaoliu phenomenon illustrates just how strongly tourism products, packaging, expectations and experiences are embedded in human culture more broadly. This applies not only for traditional customs and high culture such as the arts and literature, but also for all aspects of modern societies, including government policies, business practices, tourism product structures and choreography, attitudes to outdoor recreation, and client motivations and satisfaction. The exposure of piaoliu clients to Western whitewater rafting through the growing outbound Chinese tourism market will thus provide an excellent opportunity to study the role of culture in moulding leisure expectations, and the psychological processes when the reality proves rather different. It will thus provide an excellent opportunity for theoretical tests of culture-linked expectation disconfirmation. 


\section{References}

Arnould, E. J., \& Price, L. L. (1993). River magic: extraordinary experience and the extended service encounter. The Journal of Consumer Research, 20, 24-45.

Arnould, E. J., Price, L. L., \& Otnes, C. (1999). Making magic consumption: a study of white-water river rafting. Journal of Contemporary Ethnography, 28, 33-68.

Beedie, P., \& Hudson, S. (2003). Emergence of mountain-based adventure tourism. Annals of Tourism Research, 30, 625-643.

Boniface, P. (1998). Tourism culture. Annals of Tourism Research, 25, 746-749.

Buckley, R. C. (2006). Adventure tourism. Wallingford: CAB International.

Buckley, R. C. (2007). Adventure tourism products: price, duration, size, skill, remoteness. Tourism Management, 28, 1428-1433.

Buckley, R. C. (2009). Whitewater tourism. In B. Prideaux, \& M. Cooper (Eds.), River tourism (pp. 181-196). Wallingford: CAB International.

Buckley, R. C. (2010a). Adventure tourism management. Oxford: Elsevier.

Buckley, R. C. (2010b). Communications in adventure tour products: health and safety in rafting and kayaking. Annals of Tourism Research, 37, 315-332.

Buckley, R. C. (2010c). Conservation tourism. Wallingford: CAB International.

Buckley, R. C. (2012). Rush as a key motivation in skilled adventure tourism: resolving the risk recreation paradox. Tourism Management, 33, 961-970.

Buckley, R. C., \& Ollenburg, C. (2012). Tacit knowledge transfer: cross cultural adventure. Annals of Tourism Research, 40, 419-422. http://dx.doi.org/10.1016/j.annals.2012.08.010. 
Buckley, R. C., Zhong, L.-S., Cater, C., \& Chen, T. (2008). Shengtai luyou: cross-cultural comparison in ecotourism. Annals of Tourism Research, 35, 945-968.

Carnicelli-Filho, S., Schwartz, G. M., \& Tahara, A. K. (2010). Fear and adventure tourism in Brazil. Tourism Management, 31, 953-956.

Cater, C. I., \& Lee, Y. S. (2006). Action Asia: new paradigm or déjà-vu?. In IGU commission on tourism, leisure and global change. Retrieved 25 November 2013 from Griffith Research Online Web site http://www98.griffith.edu.au/dspace/handle/10072/14688?show=full.

Chen, B., Luo, Y. N., \& Wen, C. H. (2001). Rafting eco-tourism research: the Maling River Gorge case. Yunnan University Humanities and Social Sciences Journal, 3(27), 45-48 (In Chinese).

China Tourism Academy. (2012). Blue book of China's tourism economy (Vol. 4). Beijing: China National Tourism Administration.

China, National Statistics Bureau. (2008). Gender and education levels across various regions for the year 2008. Retrieved 23 August 2012 from China National Statistics Bureau Web site http://www.stats.gov.cn/.

Dann, G., \& Cohen, E. (1991). Sociology and tourism. Annals of Tourism Research, 18, 155169.

Farooquee, N. A., Budal, T. K., \& Maikhuri, R. K. (2008). Environmental and sociocultural impacts of river rafting and camping on Ganga in Uttarakhand Himalaya. Current Science, 94, 582-594.

Fluker, M. R., \& Turner, L. W. (2000). Needs, motivations, and expectations of a commercial whitewater rafting experience. Journal of Travel Research, 38, 380-389.

Fu, Y. Q., Tian, Y. F., \& Tong, B. (2009). Empirical research on tourists experience in outdoor whitewater drifting. Beijing Second Foreign Language Institute Journal, 5, 81-90 (In Chinese.). 
Gao, S., Huang, S., \& Huang, Y. (2009). Rural tourism development in China. International Journal of Tourism Research, 11, 439-450.

Han, F. (2006). The Chinese view of nature: tourism in China's scenic and historic interest areas. PhD Dissertation. Queensland University of Technology.

Holyfield, L. (1999). Manufacturing adventure: the buying and selling of emotions. Journal of Contemporary Ethnography, 28, 3-32.

Holyfield, L., \& Fine, G. A. (1997). Adventure as character work: the collective taming of fear. Symbolic Interaction, 20, 343-363.

Houge Mackenzie, S., \& Kerr, J. H. (2012). Client experiences in mountaineering tourism and implications for outdoor leaders. Journal of Outdoor Recreation, Education, and Leadership, 4, 112-115.

Houge Mackenzie, S., \& Kerr, J. H. (2013). Stress and emotions at work: an adventure tourism guide's experiences. Tourism Management, 36, 3-14.

Huan, X. (2007). The evolution of urban society and social changes in sports participation at the grassroots in China. International Review for the Sociology of Sport, 42(4), 441-471.

Huan, Z. W. (2009). Study on the differential development in regional drifting tourism taking seven drifting tours of Henan Province as cases. Journal of North China Institute of Water Conservancy and Hydroelectric Power (Social Science), 25(1), 56-58 (In Chinese).

Huang, S., \& Weiler, B. (2010). A review and evaluation of China's quality assurance system for tour guiding. Journal of Sustainable Tourism, 18(7), 845-860.

Hu, J. C., \& Wang, J. Q. (2008). Problems and corresponding solutions concerning rafting activities in Huangshan City. Journal of Huangshan University, 10(5), 109-111 (In Chinese). 
Jonas, L. M. (1999). Making and facing danger: constructing strong character on the river. Symbolic Interaction, 22, 247-268.

Jones, C. D., Hollenhorst, S. J., Perna, F., \& Selin, S. (2000). Validation of the flow theory in an on-site whitewater kayaking setting. Journal of Leisure Research, 32, 247-261.

Kong, B. J., Huang, J. F., \& Zhu, S. Y. (2005). An exploration of climate impact factors on Zhejiang Xianju County rafting tourism. Atmosphere Science, 4, 369-375 (In Chinese).

Lee, Y. S., \& Jennings, G. (2010). The development of leiports: leisure and sports studies and programs in tertiary education in South Korea. Journal of Teaching in Travel and Tourism, $102,125-142$.

Li, H. D., \& Bao, J. G. (1995). Rafting special tourism research and development - the case of Lechang, Guangdong. Runoff Geography, 15(2), 108-112 (In Chinese).

Lin, X. M., \& Li, J. F. (2004). Rafting tourism and evaluation of major hazards. Safety and Environment Journal, 4(2), 63-65 (In Chinese).

Li, G., \& Zhong, X. S. (2007). Feasibility analysis of establishing a Guilin sports tourism circuit. Heze University Journal, 29(2), 104-107 (In Chinese).

Lu, Z. H., \& Lin, G. Q. (2009). Analysis of drifting tourism advantages and competition of Qingyuan City in Guangdong Province. Yunnan Geographic Environment Research, 20(1), 117-121 (In Chinese).

Luo, Y. (2008). The operation strategies of tourist city: a case study of Shibin as "City of Rafting". Journal of Guizhou University for Ethnic Minorities (Philosophy and Social Science), 2, 144-146 (In Chinese).

MacCannell, D. (1976). The tourist: A new theory of the leisure class. University of California Press. 
Magee, D., \& McDonald, K. (2006). Beyond three Gorges: Nu River hydropower and energy decision politics in China. Asian Geographer, 25, 39-60.

McDonald, K. (2007). Damming China's Grand Canyon: Pluralization without democratization in the Nu River valley. PhD thesis. San Francisco: University of California Berkeley.

Midol, N., \& Broyer, G. (1995). Toward an anthropological analysis of new sport cultures: the case of whiz sports in France. Sociology of Sport Journal, 12, 204-212.

Mok, C., \& deFranco, A. L. (2000). Chinese cultural values: their implications for travel and tourism marketing. Journal of Travel and Tourism Marketing, 8, 99-114.

Nash, D., \& Smith, V. (1991). Anthropology and tourism. Annals of Tourism Research, 18, $12-25$.

Northeast Natural Resource Centre (NNRC). (1997).Wet, wild, and profitable. A report on the economic value of water-based recreation in Vermont. Montpelier, VT: NNRC.

Ollenburg, C. (2006). Horse riding. In R. C. Buckley (Ed.), Adventure tourism (pp. 305-323). Oxford: CAB International.

Ollenburg, C., \& Buckley, R. C. (2007). Stated economic and social motivations of Australian farm tourism operators. Journal of Travel Research, 45, 444-452.

PADI (Professional Association of Diving Instructors). (2012). The way the world learns to dive. Retrieved 09 August 2012 from Professional Association of Diving Instructors Web site: http://www.padi.com.

Poff, R., Larson, B. A., Spencer, S., \& Shimoda, R. (2006). All the rage: paddle your community into a new type of experience: the whitewater park. Parks \& Recreation, 41(2), $38-42$. 
Qin, J. C., Jiao, L., \& Yan, Y. F. (October 2009). Henan Nanyang rafting preliminary study. Zaozhuang University Journal, 140-144 (In Chinese).

Qiu, J. (2012). Trouble on the Yangtze. Science, 336(6070), 288-291.

Ryan, C., \& Huang, S. (2013). Tourism in China: Destinations, planning and experiences. Bristol: Channel View.

Salazar, N. B. (2012). Community based cultural tourism: Issues and opportunities. Journal of Sustainable Tourism, 20, 9-22.

Serenari, C., Leung, Y. F., Attarian, A., \& Franck, C. (2012). Understanding environmentally significant behaviour amongst white-water rafting and trekking groups in the Garhwal Himalayas, India. Journal of Sustainable Tourism, 20, 757-772.

Shan Shui Society, \& Liu, J. Q. (2011). A river memoir. Beijing: Encyclopaedia of China Publishing House, ISBN 9787500087588 (In Chinese).

Siderelis, C., \& Moore, R. L. (2006). Examining the effects of hypothetical modifications in permitting procedures and river conditions on whitewater boating behavior. Journal of Leisure Research, 38, 558-575.

Sofield, T. H. B., \& Li, S. (1998). Tourism development and cultural policies in China. Annals of Tourism Research, 25, 362-392.

Sofield, T. H. B., \& Li, S. (2011). Tourism governance and sustainable national development in China: a national-level synthesis. Journal of Sustainable Tourism, 19, 501-534.

Stone, R. (2011). Mayhem on the Mekong. Science, 333, 814-818.

Stronza, A. (2001). Anthropology of tourism: forging new ground for ecotourism and other alternatives. Annual Review of Anthropology, 30, 261-283. 
Swarbrooke, J., Beard, C., Leckie, S., \& Pomfret, G. (2003). Adventure tourism: The new frontier. Oxford: Butterworth Heinemann.

Thompson, M. (2012). Opening speech, China outbound tourism and travel market annual conference, April 2012. Retrieved 04 August 2012 from China Outbound Tourism and Travel Market Web site: http://www.cottm.cn/press/press_20120418_en.html.

UNESCO. (2012). UIS statistics in brief: Education (all levels) profille - China. Retrieved 18 August 2012 from UNESCO Web site:

http://stats.uis.unesco.org/unesco/TableViewer/document.aspx?ReportId=121\&IF_Language =eng\&BR_Country=1560.

Vespestad, M. K., \& Mehmetoglu, M. (2010). The relationship between tourist nationality, cultural orientation and nature-based tourism experiences. European Journal of Tourism Research, 3, 87-104.

Wang, R. Q. (December 2005). Research and considerations regarding Dong River rafting tourism development. Hunan Institute Journal, 102-105 (In Chinese).

Wen, C. H., Chen, H. Y., \& Yang, Y. (2002). Maling River Gorge rafting adventure ecotourism development research. Economic Geography, 22(1), 111-14 (In Chinese).

Winter, T. (2009). Asian tourism and the retreat of Anglo-western centrism in tourism theory. Current Issues in Tourism, 12, 21-31.

Wu, Y. (2007). Research of drifting tourism in Anhui Province. Journal of Anhui Agricultural University (Social Science Edition), 2, 22-25, 67. (In Chinese).

Wu, C. H.-J., \& Liang, R. D. (2010). The relationship between white-water rafting experience formation and customer reaction: a flow theory perspective. Tourism Management, 32(2), 317-325.

Xia, D., \& Liu, Y. F. (2009). Perspectives on rafting culture and sports tourism from a Tujia minority rafting region. Hubei Sports Science and Technology, 1, 79-80 (In Chinese). 
Yang, H., Huang, J., Li, S. Q., \& Chen, Y. Z. (2006). Study on development of drift tourism in western Hunan Province. Resource Development and Market, 5, 486-488 (In Chinese).

Yang, L., \& Wall, G. (2008). Ethnic tourism and entrepreneurship: Xishuangbanna, Yunnan, China. Tourism Geographies, 10(4), 522-544.

Zhou, H., Luo, M. C., \& Chen, Q. D. (2007). Tourism interpretation systems - a case study of Yangmingshan Rafting. Guilin Tourism College Journal, 1, 55-58 (In Chinese).

Zong, W., \& Zhi, G. (2007). A case study of rafting on Fujian's Taining Stream. Guilin Tourism College Journal, 18(1), 49-51 (In Chinese). 
Ralf Buckley holds the International Chair in Ecotourism Research at Griffith University. He has worked in China since 1983, and during 2014 is International Visiting Professor at the Chinese Academy of Sciences.

Kristen McDonald holds a PhD from Berkeley and a BA from Yale. During this study she was Visiting Fellow at the International Centre for Ecotourism Research, Griffith University. Currently, she manages China programs for the US-based NGO Pacific Environment.

Duan Lian lectures at the Institute of Ecological Tourism, Southwest Forestry University, Kunming. His masters degree and research interests are in outdoor sports and adventure tourism, including the development of river tourism in Yunnan Province.

Sun Lin holds a Masters in Ecotourism from Southwest Forestry University. Her thesis examined customer experience in commercial rafting trips on the Maling River, Guizhou.

Chen Lan Xue holds a Masters in Ecotourism from Southwest Forestry University. Her thesis examined customer understanding of safety issues for rafting on the Maling River, Guizhou. 
Table 1a. Piaoliu Enterprises Audited

Identifier Company name County, province $\quad \begin{aligned} & \text { Hours to town } \\ & \text { (population) }\end{aligned}$

$\begin{array}{lll}\text { Hongkou } & \text { Chengdu Feilai Mountain Hongkou, Sichuan } & 2 \mathrm{hr} \text {, Chengdu } \\ & \text { Raft Co. } & (14 \text { million) }\end{array}$

Huangteng Huangteng Gorge Rafting Qingyuan, Guangdong 2 hr, Guangzhou (16 million)
Xuanzhen Pure Xuanzhen Old Cave Qingyuan, Guangdong 2 hr, Guangzhou Rafting (16 million)

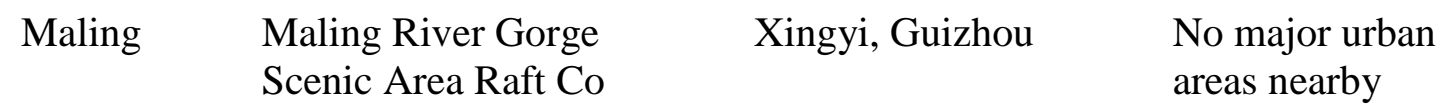

Maoyan Maoyan River Rafting Zhangjiajie, Hunan $32 \mathrm{~km}, 1 \mathrm{hr}$, Zhangjiajie (major tourist area)

$\begin{array}{llll}\text { Mengdong } & \text { Mengdong River Rafting } & \text { Zhangjiajie, Hunan } & 80 \mathrm{~km}, 2 \mathrm{hr} \text {, Zhangjiajie } \\ \text { Jiuwan } & \text { Jiuwan Brook Rafting } & \text { Zigui, Hubei } & \begin{array}{l}3 \mathrm{hr} \text {, Yichang } \\ \text { (4 million) }\end{array}\end{array}$


Table 1b. Piaoliu Watercourses

\begin{tabular}{|c|c|c|c|c|c|c|c|}
\hline Name & $\begin{array}{l}\text { Flow } \\
\mathbf{m}^{3} \mathbf{s}^{-1}\end{array}$ & $\begin{array}{l}\text { Rapid } \\
\text { class }^{\text {a }}\end{array}$ & $\begin{array}{l}\text { Watercourse } \\
\text { modification }\end{array}$ & $\begin{array}{l}\text { Flow } \\
\text { control }^{b}\end{array}$ & $\begin{array}{l}\text { Peak } \\
\text { season }\end{array}$ & $\begin{array}{l}\text { Length, } \\
\text { km }\end{array}$ & $\begin{array}{l}\text { Time, } \\
\text { hrs }\end{array}$ \\
\hline Hongkou & 16 & II & moderate & no & Apr-Oct & 5 & 1.0 \\
\hline Huangteng & 0.8 & manmade & extensive & yes & Apr-Oct & 5 & 1.5 \\
\hline Xuanzhen & 0.8 & manmade & extensive & yes & Apr-Oct & 3 & 1.5 \\
\hline Maling & 80 & IV & minimal & no & May-Oct & 15 & 1.5 \\
\hline Maoyan & $\sim 80$ & II & minimal & no & Apr-Oct & 15 & 1.5 \\
\hline Mengdong & $\sim 50$ & II & minimal & yes & Mar-Oct & 10 & 2.5 \\
\hline Jiuwan & $\sim 4$ & manmade & moderate & yes & May-Oct & 6.5 & 3.0 \\
\hline
\end{tabular}

${ }^{a}$ International scale, Class I (easiest) to Class V (most difficult).

${ }^{\mathrm{b}}$ By dams built upstream of the rafting section. Huangteng and Xuanzhen can be completely dewatered at night. 
Table 1c. Piaoliu Tour Products

\begin{tabular}{|c|c|c|c|c|c|c|c|c|}
\hline Name & $\begin{array}{l}\text { Price } \\
\text { per pax, } \\
\text { CNY, } \\
\text { modal }\end{array}$ & $\begin{array}{l}\text { Clients } \\
\text { per day, } \\
\text { mean } \\
\text { max }\end{array}$ & $\begin{array}{l}\text { Life } \\
\text { guards } \\
\text { on } \\
\text { banks }\end{array}$ & $\begin{array}{l}\text { Raft } \\
\text { shape, } \\
\text { O, P }\end{array}$ & $\begin{array}{l}\text { Raft } \\
\text { size, } \\
\text { pax }\end{array}$ & $\begin{array}{l}\text { Client } \\
\text { paddle }\end{array}$ & Guide & Steering \\
\hline Hongkou & 170 & 3000 & 20 & $\begin{array}{l}\mathrm{O} \\
\mathrm{P}\end{array}$ & $\begin{array}{l}2 \\
9\end{array}$ & $\begin{array}{l}\text { yes } \\
\text { no }\end{array}$ & $\begin{array}{l}\text { no } \\
\text { yes }\end{array}$ & $\begin{array}{l}\text { paddle } \\
\text { paddle }\end{array}$ \\
\hline Huangteng & 260 & 10,000 & 136 & $\mathrm{O}$ & 2 & no & no & none \\
\hline Xuanzhen & 168 & 8000 & 50 & $\mathrm{O}$ & 2 & no & no & none \\
\hline Maling & 160 & 600 & 0 & $\mathrm{P}$ & $8-15$ & no & yes & pole/paddle \\
\hline Maoyan & 180 & 3000 & 0 & $\mathrm{P}$ & $8-10$ & no & yes & motor \\
\hline Mengdeng & 122 & 4000 & 0 & $\mathrm{P}$ & $8-10$ & no & yes & pole/paddle \\
\hline Jiuwan & 180 & 7000 & $30-60$ & $\mathrm{O}$ & 2 & yes & no & paddle \\
\hline
\end{tabular}

${ }^{\mathrm{a}} \mathrm{O}=$ Oval, $\mathrm{P}=$ Pontoons, 2 or 3 . Pontoon rafts have guides with poles, paddles, or motor. $\mathrm{CNY}=$ Chinese renmimbi yuan. CNY $6.3=$ USD 1.00 as of August 2013. 
Table 1d. Piaoliu Enterprise Structure and Site Access

\begin{tabular}{|c|c|c|c|}
\hline Name & Enterprise structure & Access to Land & Access to Water \\
\hline Hongkou & private corporation & longterm lease & 20-year lease \\
\hline Huangteng & private corporation & $\begin{array}{l}\text { leases from farmers } \\
\text { and government }\end{array}$ & 30-year contract \\
\hline Xuanzhen & private corporation & 20-year lease & long-term contract \\
\hline Maling & $\begin{array}{l}\text { county government } \\
\text { enterprise }\end{array}$ & $\begin{array}{l}\text { concession in county } \\
\text { scenic area }\end{array}$ & $\begin{array}{l}\text { concession in county } \\
\text { scenic area }\end{array}$ \\
\hline Maoyan & private corporation & $\begin{array}{l}\text { development rights in } \\
\text { scenic area }\end{array}$ & 50-year use rights \\
\hline Mengdeng & $\begin{array}{l}\text { county government } \\
\text { enterprise }\end{array}$ & $\begin{array}{l}\text { long-term use rights } \\
\text { from local government }\end{array}$ & $\begin{array}{l}\text { long-term use rights } \\
\text { from local government }\end{array}$ \\
\hline Jiuwan & $\begin{array}{l}\text { government/private } \\
\text { partnership }\end{array}$ & $\begin{array}{l}\text { land provided by } \\
\text { government partner }\end{array}$ & $\begin{array}{l}\text { long-term use rights } \\
\text { from government }\end{array}$ \\
\hline
\end{tabular}




\section{Component or Characteristic Western Whitewater Rafting Chinese Piaoliu Products}

Access to river

Watercourses

River flow, $\mathrm{m}^{3} \mathrm{~s}^{-1}$

Rafts, main type

Rafts, alternative type

Propulsion and steering

Disembarkation

Safety equipment

Rescuing swimmers

Client clothing

Typical trip duration

Typical daily client volume

Waste management

Enterprise structure

Marketed as a type of:

Bookings mainly by:

Sold as part of package

Subsector associations non-exclusive

natural

$20-3000$

large, oval, self-bailing

two-pontoon catarafts with oar frame

guide oars or client paddles, rarely motors, never poles

row actively to riverbank, moor

legal standards, client training, strict rules followed well

from river, by raft guide or from bank, by lifeguards safety kayakers

provided or specified by tour operator for warmth and safety

half, full or multiple days

tens to hundreds

generally little litter or waste

private firms

adventure tourism

independent $>$ groups

rarely, with other adventure activities

nature, outdoors, adventure, escape, excitement, mass specialist exclusive

engineered

$0.8-80$

small, oval, non-bailing

multi-pontoon rafts, sit astride

none, guide pole and paddle, or motor; rarely client paddles

flushed onto concrete ramp, automatically

rarely specified or provided, often inappropriate or inadequate

1-3 hours

thousands to over ten thousand

high volume of litter accumulation

private, government or mixed

shengtai luyou, ecotourism

groups > independent

commonly as part of "package" of non-adventure activities tourism 
Figure 1. Piaoliu participants' motivations

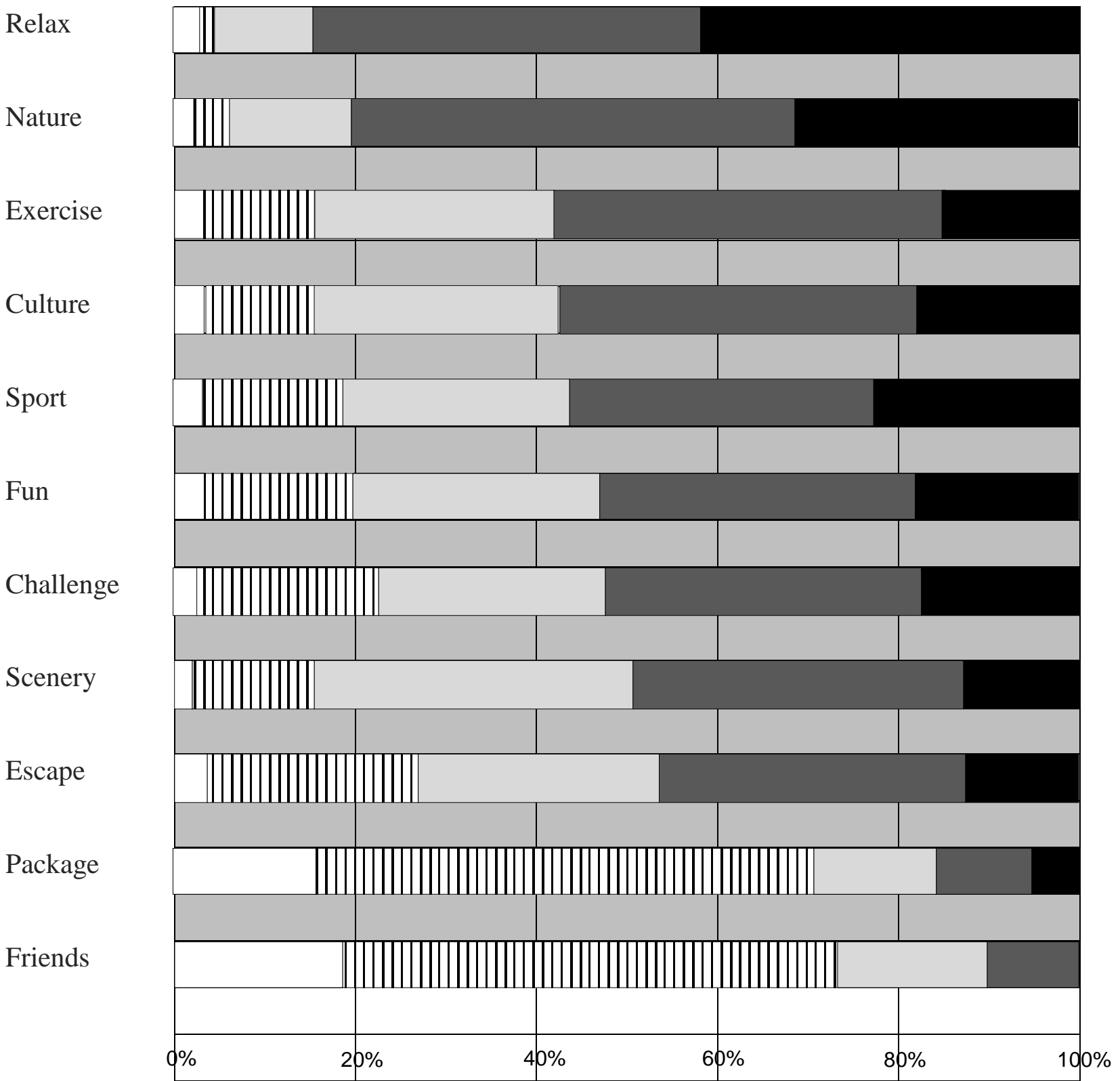

\begin{tabular}{|l|l|}
\hline$\square$ & not at all important \\
\hline Ul & not important \\
\hline$\square$ & somewhat important \\
\hline$\square$ & important \\
\hline $\mathbf{\square}$ & very important \\
\hline & $\mathrm{n}=1100$ \\
\hline
\end{tabular}


Figure 2. Piaoliu Participants' Satisfaction

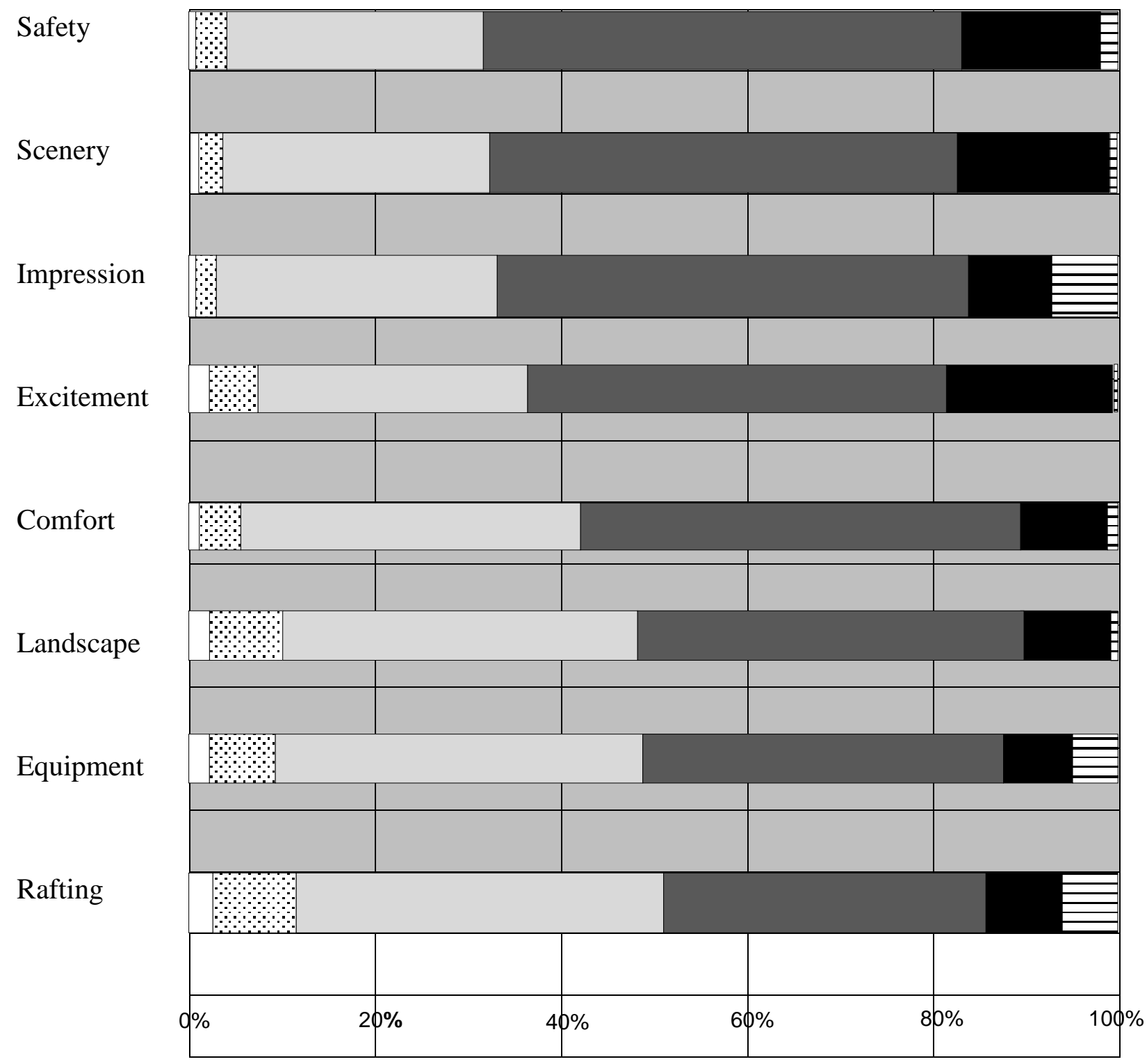

\begin{tabular}{|ll|}
$\square$ & not at all satisfied \\
$\square$ & not satisfied \\
$\square$ & somewhat satisfied \\
$\square$ & satisfied \\
& very satisfied \\
$\square$ & missing \\
& $\mathrm{n}=1100$ \\
\hline
\end{tabular}

